\title{
VIOLÊNCIA DE GÊNERO E DESIGUALDADE RACIAL EM UMA PESQUISA COM MULHERES NO TERRITÓRIO CONFLAGRADO DO CONJUNTO DE FAVELAS DA MARÉ/RIO DE JANEIRO'
}

\author{
Miriam Krenzinger ${ }^{2}$ \\ Patrícia Farias ${ }^{3}$ \\ Rosana Morgado ${ }^{4}$ \\ Cathy Mcllwaine ${ }^{5}$
}

\begin{abstract}
Resumo
Este artigo apresenta resultados de pesquisa realizada entre 2016 e 2018 sobre percepções de mulheres moradoras do conjunto de favelas da Maré, no Rio de Janeiro, quanto à violência de gênero, suas manifestações e formas de enfrentamento. Considerando que mulheres pretas e pardas são mais suscetíveis de serem afetadas, verificou-se que os tipos de violência e os locais onde se manifestam são resultado de condições econômicas e relacionais, em geral no ambiente doméstico/familiar e perpetradas por pessoas conhecidas pela vítima. Os processos de violência também se relacionam estruturalmente à ausência de políticas públicas e à ação de grupos armados, que reforçam múltiplas desigualdades sociais.

Palavras-chave: Violências de Gênero; Desigualdade racial; Conflitos armados.

\section{VIOLENCIA DE GÉNERO Y DESIGUALDAD RACIAL EN UNA INVESTIGACIÓN CON MUJERES DEL TERRITORIO CONFLAGRADO DEL CONJUNTO DE BARRIOS DE MARÉ / RIO DE JANEIRO}

\section{Resumen}

Este artículo presenta los resultados de las investigaciones realizadas entre 2016 y 2018 sobre las percepciones de mujeres residentes en las favelas de Maré, en Río de Janeiro, sobre la violencia de

1 Artigo recebido em 30/11/2020. Primeira avaliação em 07/12/2020. Segunda avaliação em 17/12/2020. Aprovado em 13/01/2021. Publicado em 25/02/2021.

DOI: https://doi.org/10.22409/tn.v19i38.47366.

2 Miriam Krenzinger é professora do Programa de Pós-Graduação de Serviço Social da Escola de Serviço Social da Universidade Federal do Rio de Janeiro/UFRJ. Realizou pós-doutorado em Antropologia do Direito, na Universidade de Brasília (UnB, 2016-2017); e em Ciência Política, pelo Instituto Universitário de Pesquisas do Rio de Janeiro; e Doutora em Serviço Social (PUC/RS).

E-mail: m.krenzinger@ess.ufrj.br. Lattes: http://lattes.cnpq.br/3658926460189319. ORCID: https://orcid.org/0000- 0002-1935-2976.

${ }^{3}$ Patrícia Silveira de Farias é professora do Programa de Pós-Graduação em Serviço Social/UFRJ, com pós-doutorado em Antropologia Social (UFRGS) e em Geografia Humana (King's College London), doutora em Antropologia Cultural e coordenadora do Grupo de Pesquisa CNPq Sociabilidades Urbanas, Espaço Público e Mediação de Conflitos (GPSEM). E-mail: trapfarias@gmail.com.

Lattes: http://lattes.cnpq.br/2927612633388671. ORCID: https://orcid.org/0000-0002-3669-7626.

${ }^{4}$ Rosana Morgado é professora do Programa de Pós-Graduação de Serviço Social da Escola de Serviço Social da Universidade Federal do Rio de Janeiro/UFRJ e coordenadora do Núcleo de Pesquisa NETIJ/ESS/UFRJ. Realizou pós-doutorado nas Universidades de Hertfordshire/ Inglaterra (2010) e na King's College/Inglaterra (2020). Mestrado em Serviço Social, pela UFRJ (1992) e doutorado pela PUC/SP (2001). E-mail: rmorgadopaiva@hotmail.com.

Lattes: http://lattes.cnpq.br/4281701886369977. ORCID: https://orcid.org/0000-0002-3094-9802

${ }^{5}$ Cathy Mcllwaine é professora da Faculdade de Ciências Sociais e Políticas Públicas da King's College London, Departamento de Geografia. Mestre em Estudos Latino-Americanos pela University of Liverpool e Doutora pela London School of Economics. E-mail: cathy.mcilwaine@kcl.ac.uk

ORCID: https://orcid.org/0000-0001-6528-599X 
género, sus manifestaciones y formas de prevención. Considerando que las mujeres negras y pardas tienen más probabilidades de verse afectadas, se concluyó que los tipos de violencia y los lugares donde se manifiestan resultan de condiciones económicas y relacionales, generalmente en el ámbito doméstico/familiar y perpetradas por personas conocidas por la víctima. Los procesos de violencia también están estructuralmente relacionados con la ausencia de políticas públicas y con la acción de grupos armados, los cuales refuerzan diversas desigualdades sociales.

Palabras clave: Violencias de género; Desigualdad racial; Conflictos armados.

\title{
GENDER VIOLENCE AND RACIAL INEQUALITY IN A RESEARCH WITH WOMEN IN THE CONFLAGRATED TERRITORY OF THE SET OF SLUMS OF MARÉ / RIO DE JANEIRO
}

\begin{abstract}
This article presents results of a research conducted between 2016 and 2018 on the perceptions of women living in favelas of Maré, in Rio de Janeiro, regarding gender-based violence, its forms of manifestation and prevention. Considering the fact that black and mixed-race women are more likely to be affected, the research findings revealed that the types of violence and the places where they occur are the result of economic and relational conditions, generally in the domestic/family environment and perpetrated by people known by the victim. The incidence of violence is also structurally related to the absence of public policies and to the action of armed groups, which reinforce multiple social inequalities. Keywords: Gender-based violence; Racial inequality; Armed conflicts.
\end{abstract}

\section{Introdução}

Este artigo objetiva articular algumas reflexões teórico-metodológicas a respeito de gênero, cor/raça e local de moradia, suscitadas a partir da pesquisa de amplo escopo, intitulada Cidades saudáveis, seguras e com equidade de gênero: perspectivas transnacionais sobre violência urbana contra mulheres e meninas (VCMM) no Rio de Janeiro e em Londres, ${ }^{6}$ desenvolvida entre novembro de 2016 e abril de 2018.

Com base nesse estudo, que mobilizou inúmeros/as pesquisadores/as de instituições do Brasil e do Reino Unido, em diferentes fases de formação, e que se constituiu a partir de metodologia qualitativa e quantitativa, com pesquisa de campo e surveys em ambas as cidades, fez-se aqui um recorte que visa destacar elementos relativos à experiência metodológica e analítica sobre violências de gênero em meio

\footnotetext{
${ }^{6}$ Financiada pelo Economic and Social Research Council (ESRC) e pelo Newton Fund, a pesquisa foi realizada entre novembro de 2016 e abril de 2018, a partir da parceria entre a Escola de Serviço Social (UFRJ), a Organização não governamental Redes de Desenvolvimento da Maré, o People's Palace Project (Queen Mary University of London) e o King's College London University. Como objetivo principal, buscou-se conhecer a percepção das mulheres, moradoras da Maré e de brasileiras que residem em Londres, sobre o fenômeno da violência, seus contextos e formas de manifestações, bem como mapear a rede de atendimento às mulheres vítimas de violência oferecida nas duas cidades. $\mathrm{A}$ pesquisa, de natureza interdisciplinar e interinstitucional foi realizada por três equipes de pesquisadores: a) Pesquisadoras da Escola de Serviço Social/ UFRJ- Joana Garcia, Miriam Krenzinger Rosana Morgado; b) Pesquisadores/as da Queem Mary University e Kings Kollege - Cathy Mcilwany, Paul Heritage e Yara Evans; c) Pesquisadores da Redes da Maré/ Casa das Mulheres da Maré: Bianca Polotto Cambiaghi, Dalcio Marinho Gonçalves, Eliana Sousa Silva, Gisele Ribeiro Martins, Isabela Souza da Silva. Assistentes de Pesquisa: Andreza da Silveira Jorge, Alessandra Pinheiro, Juliana Alves Sá, Kelly San Tereza Onä.
} 
a um lócus complexo, marcado por conflitos urbanos, pela violência armada e por segregações sócio raciais. Desta forma, o presente artigo lida com as informações da pesquisa realizada com mulheres das favelas da Maré - maior conjunto de favelas da capital fluminense - e, particularmente, mulheres negras. Assim, pretende-se refletir sobre as condições e o contexto de vida destas mulheres, analisando as relações étnico-raciais, de gênero, de classe e as múltiplas dimensões da violência, com destaque para a questão da violência armada.

A Maré é uma unidade territorial administrativa da cidade do Rio de Janeiro, que ocupa uma área de quase $4 \mathrm{~km}^{2}$ e abrange 16 favelas do chamado "Complexo de favelas da Maré", configurando-se como o maior conjunto de favelas da capital fluminense. Na pesquisa de campo, utilizamos um conjunto de estratégias de coleta de dados: mapeamento dos principais serviços públicos ativados na rede de apoio às mulheres em situações de violência; survey conduzido por cinco assistentes de pesquisa que aplicaram 801 questionários em visitas domiciliares em 15 comunidades Maré7; entrevistas semiestruturadas com 20 mulheres moradoras da(s) Maré(s) vítimas de violência, e realização de sete grupos focais compostos por um total de 59 participantes com perfis diversificados. Como resultado, esta experiência empírica complexa propiciou a identificação de uma série de fatores relativos a causas, tipos, formas, multidimensionalidade e implicações da violência de gênero em contextos de alta complexidade social. Neste artigo, destacamos justamente as questões relativas a territorialidade urbana racializada, precariedade infraestrutural e desigualdade de acesso a direitos. Outras dimensões podem ser encontradas em Krenzinger et al. (2018) e Mcllwaine et al. (2020).

Segundo dados do Censo Maré $2013^{8}$, as mulheres e meninas moradoras da Maré são 70.900 (das quais 49.932 têm mais de 18 anos), no universo de 139.073 pessoas. Assim, elas representam $51 \%$ dos moradores desse conjunto de favelas que

\footnotetext{
7 Das 16 favelas que compõem o Complexo da Maré, apenas Marcílio Dias não participou da pesquisa. Em 1994, a Maré passou a ser tratada como uma área totalmente urbanizada, com alterações nos limites dos bairros de Olaria, Ramos, Bonsucesso e Manguinhos. Essa condição viabilizou a criação do bairro, composto por um conjunto de 15 localidades: Praia de Ramos, Parque Roquete Pinto, Parque União, Parque Rubens Vaz, Nova Holanda, Parque Maré, Nova Maré, Baixa do Sapateiro, Morro do Timbau, Conjunto Bento Ribeiro Dantas, Conjunto Pinheiro, Vila dos Pinheiros, Novo Pinheiro (popularmente chamado Salsa e Merengue), Vila do João e Conjunto Esperança. A delimitação não inclui o território da comunidade de Marcílio Dias, que pertence ao bairro da Penha Circular (Fernandes, 2015).

${ }^{8}$ REDES DA MARÉ. Censo da Maré 2013. Observatório de Favelas. Disponível em:

<https://redesdamare.org.br/censomare/
} 
se configura, a partir do número total de habitantes, maior do que mais de $90 \%$ dos municípios brasileiros. Para lidar com este locus, o questionário acima mencionado foi aplicado por cinco entrevistadoras, todas com experiência em pesquisa tipo survey, sendo duas delas moradoras do Complexo da Maré. Em relação a estas, a região coberta não coincidiu com seu lugar de moradia, de modo a evitar o contato com mulheres conhecidas. A escolha de mulheres para conduzirem o levantamento foi uma estratégia para favorecer a proximidade com as pessoas entrevistadas, especialmente em função do tema central da pesquisa.

A pesquisa adotou como pressupostos teóricos que a violência contra a mulher (VCM), por ser um fenômeno complexo e multidimensional, está relacionada à questão do medo e da insegurança urbana (MOSER e MCILWAINE, 2004), expressando diferenças socialmente construídas entre os gêneros, etnias e raças, assim como na divisão sexual do trabalho. As formas da violência (física, psicológica e simbólica) e os contextos das suas manifestações (doméstico, urbano, institucional) decorrem, principalmente, de fatores econômicos, culturais e relacionais. É comum a violência ocorrer em âmbito privado, dentro da própria casa da menina, jovem ou da mulher, envolvendo namorados, cônjuges, parentes e/ou amigos próximos de seus familiares (SAFFIOTI, 1999). Conforme Almeida (2007), a violência doméstica remete ao espaço onde a violência se manifesta, ou seja, na esfera privada. Já a violência intrafamiliar caracteriza-se mais do que o espaço, diz respeito às relações envolvidas na dinâmica violenta. Esta última pode compreender pessoas que não necessariamente integrem determinado núcleo familiar, mas que com ele convivem de forma comunitária.

A violência interpessoal pode se dar no espaço sociocupacional de trabalho, nas escolas, universidades, instituições religiosas e outros espaços da vida comunitária onde os atos são encobertos pelo sigilo, pelo medo e pela baixa visibilidade (Almeida, 2007). As expressões de violências que se manifestam nesses contextos podem ser de diferentes formas: psicológica, simbólica, assédio verbal e físico, podendo ser até letal. Englobam-se, nessa ótica, os processos e dinâmicas sociais e interpessoais de violência e as respostas dadas pelos agentes do Estado e por diferentes grupos societários (com destaque para os grupos armados), estando relacionadas novamente a questões de classe social, raça/etnia e orientação sexual, entre outras categorias socialmente construídas. 
Também foi considerado na pesquisa aqui relatada que os papéis impostos às mulheres e aos homens, consolidados ao longo da história e reforçados pelo patriarcado e sua ideologia, induzem ao estabelecimento de relações violentas entre os gêneros, que é fruto do processo de socialização dos indivíduos. Nessa mesma linha, considera-se que as construções sociais, tanto da feminilidade quanto da masculinidade, estão conectadas ao fenômeno da violência urbana, especialmente em territórios em conflitos armados. A generalização da violência machista e sexista contribui para que algumas mulheres culpabilizem as vítimas, reproduzindo a violência que as oprime. Posto isso, a violência contra as mulheres decorre de uma relação abusiva de poder exercida, de forma dinâmica, tanto por homens como por mulheres, ainda que de forma desigual.

As relações entre sujeitos inseridas desigualmente na estrutura familiar e comunitária subjugam, tendencialmente, o "mundo do feminino" (entendendo não só como de mulheres cisgênero, ${ }^{9}$ mas incluindo aí homens "afeminados", gays, travestis e mulheres trans). A maioria das vítimas de violência de gênero são as mulheres e, ainda, a família e o espaço doméstico, de maneira geral, são territórios vulneráveis ao domínio das armas e à reprodução de circunstâncias enquadradas como tal. Além disso, há consonância entre as violências física e simbólica, uma vez que a primeira não se mantém sem que a segunda seja a base legitimadora do uso da força física. No caso da violência de gênero, a dimensão simbólica é fundamental para sua compreensão e usada como legitimação, pois "a ordem simbólica favorece o exercício da exploração e da dominação" (ALMEIDA, 2007) de homens sobre mulheres.

\section{O conjunto de Favelas da Maré na cidade do Rio de Janeiro, campo da pesquisa}

A palavra "favela" tem um peso simbólico já reconhecido internacionalmente. Desta forma, falar em "favela" em relação à Maré significa frisar sua instável inserção no composto da cidade do Rio de Janeiro, em termos de direitos de cidadania e da (in)existência de equipamentos públicos para garantir tais direitos - como água, luz, esgoto, escolas, postos de saúde, ruas asfaltadas e segurança pública. Nesta direção,

\footnotetext{
${ }^{9}$ Pessoa cisgênero: pessoa que foi designada com um gênero ao nascer e se identifica com ele. Sinônimo de cissexual. Abreviado como "cis". Pessoa transgênero: pessoa que foi designada com um gênero ao nascer e não se identifica com ele (GUIMARÃES, 2013).
} 
o trabalho de campo na "favela"10 desenvolveu-se num território associado à precariedade da presença do Estado e, por conseguinte, da própria fragilidade de seus moradores. Para o senso comum, porém, a questão da desigualdade de acesso a bens e serviços parece se ampliar abarcando uma questão "moral": de um lado, os moradores destes locais são associados a comportamentos criminosos, no que já se configurou na chamada "criminalização da pobreza" (WACQUANT, 2001). De outro lado, esta mesma precariedade leva a uma forma de identificação de seus moradores como "vítimas". Assim, desenham-se dois "lugares sociais" - e apenas dois, frise-se - possíveis para estes cidadãos: o de "criminoso" ou o de "vítima da sociedade". Embora se diferenciem comportamentos ligados à legalidade ou à ilegalidade, ambos os rótulos têm algo em comum: associam aspectos morais às condições objetivas de existência destas pessoas, traçando e apresentando um perfil preconcebido de suas práticas e vivências cotidianas.

Não é um procedimento incomum, em se tratando de habitações populares. De fato, como Roy (2018) afirma em seu ensaio crítico sobre a proposta do urbanismo subalterno, "favela" se tornou uma metonímia para variadas formas de reafirmação da desigualdade, inclusive aquela, mais sutil, ligada a um suposto "caráter subalterno" que nega potência e agência a todas as alternativas postas em jogo em ambientes de precariedade. Mais ainda: sinaliza um pertencimento precário ao próprio cenário urbano mundial - assim, "favela" se torna um ícone da chamada "megacidade global", aquela cidade caótica, desorganizada, com pessoas das mais variadas origens e "impossível" de ser habitada, a que se referem urbanistas, gestores, financistas, quando se trata de grandes metrópoles do Sul Global. Enquanto isso, as grandes cidades europeias ou americanas, ainda de acordo com o ensaio de Roy, são aquelas com grande população, de diferentes origens, e com problemas urbanos sérios - mas que são chamadas de "cidades globais".

As favelas brasileiras não se apresentam de forma diferente. Embora cercadas, muitas vezes, pela falta de recursos e de acesso a bens públicos, seus moradores se expressam em busca de direitos e pela garantia de seus interesses. Além disso, longe de se apresentarem como territórios uniformemente "despossuídos" e precários, tais

\footnotetext{
${ }^{10}$ A favela, com base em Jailson Silva (2009), foi definida como um território com implenitude de políticas e ações do Estado, precariedade em investimentos, como resumo das condições desiguais da urbanização e configuração de um território com identidades plurais com expressiva presença de negros e indígenas.
} 
lugares da cidade se inserem em intrincadas hierarquias locais, que é preciso compreender a fim de analisar com mais propriedade as realidades aí inscritas.

O caráter complexo da territorialidade na cidade do Rio de Janeiro e, particularmente, sua articulação com processos de atribuição de comportamentos a partir do local de moradia já foram indicados em diversos estudos (FARIAS e CECCHETTO, 2009, por exemplo). Assim, é preciso reconhecer que há uma dicotomia mais ampla da cidade, já demonstrada na literatura, que divide bairros "superiores" hierarquicamente, na Zona Sul do Rio de Janeiro (Ipanema, Leblon e Copacabana, mas a Barra da Tijuca, que administrativamente se situa na Zona Oeste, mas é simbolicamente alocada neste vetor) e os bairros situados na base da escala hierárquica, aqueles pertencentes à Zona Norte/subúrbios. No entanto, dentro da mesma escala, alguns bairros são mais "bem situados" que outros; desta forma, morar na Tijuca é "melhor" que morar em Japeri, por exemplo.

Desta intrincada hierarquia local, as favelas também participam; assim, morar numa favela da Zona Sul, como Rocinha ou Chapéu Mangueira, ou dos "melhores bairros" da Zona Norte, como o Borel, na Tijuca, não é o mesmo que morar numa favela mais periférica, como Acari. O critério de proximidade com a Zona Sul como definidor de uma posição mais favorável é compreensível, no sentido de que as favelas ali localizadas usufruem, ao menos em parte, dos equipamentos públicos urbanos destinados aos moradores abastados. No entanto, vale lembrar que, também aqui, o espectro dos comportamentos "desordeiros" ou simplesmente criminosos ronda e sobressai, mesmo sobre aqueles e aquelas moradores/as das favelas da Zona Sul.

A expressão carioca "morar mal" ou "morar bem" sugere uma hierarquia territorial, ao mesmo tempo que a perpetua. Quem mora no Complexo da Maré, portanto, "mora mal", no senso comum dos habitantes da cidade do Rio de Janeiro, já que se trata de um conjunto de favelas que não se localiza na Zona Sul. Isso significa dizer que, ao fazer um trabalho de campo neste território, há de se levar em conta os processos simbólicos da classificação dos espaços urbanos; dito de outra maneira, é preciso reconhecer que a ampliação do alcance destas vozes locais já se torna um ato político, pois perturba os lugares sociais de visibilidade/invisibilidade previamente concebidos. Entretanto, é necessário destacar que estes espaços e lugares sociais 
não se encontram vazios; há uma série de grupos, organizações, redes de sociabilidade, que circulam, agitam e dão suporte a reivindicações, medos e sonhos.

Neste sentido, a opção do grupo de pesquisa em se articular a uma rede local não é simplesmente uma escolha pragmática - de permitir mais facilmente o acesso às mulheres. Tratou-se de analisar o que existe, como mulheres e homens construíram formas de lidarem com a ausência de equipamentos e serviços públicos e, consequentemente, com a dificuldade de acesso a direitos - no caso, o direito à segurança e a viver sem violência. Por sua vez, as participantes reconhecem a validade do trabalho científico como possibilidade de ampliar o alcance do saber local e dar visibilidade a suas ações, além da importante troca de informações e de conhecimento. Dessa forma, reconhece-se como fundamental a participação da Redes da Maré, localizada na Nova Holanda, como parte integrante da coordenação da pesquisa, tanto pelos motivos anteriormente enunciados, como por possibilitar a continuidade/reestruturação de ações que já estavam sendo desenvolvidas na Casa das Mulheres, ${ }^{11}$ situada em local próximo, o Parque União.

Como Simone (2004) sugere, as pessoas podem ser consideradas como infraestrutura local, no sentido de que se trata de um repertório de saberes e práticas, formas de agir, que se aglutinam num conhecimento local, um patrimônio que enforma as vivências cotidianas, um trunfo que pode e é usado para negociar saídas em um ambiente conflituoso e inóspito muitas vezes. Prestar atenção neste tipo de infraestrutura, nos saberes e fazeres locais constitui uma estratégia ao mesmo tempo ética, metodológica e heurística, com pesquisa em diversas fontes e documentos.

É nesta perspectiva que se entende a dimensão de um trabalho acadêmico transdisciplinar: uma pesquisa que atravessa as já reconhecidas áreas do conhecimento científico, mas que abrange ainda o reconhecimento de outros saberes, como o militante, o religioso, o tradicional, o cotidiano como igualmente válidos e importantes, em busca do enfrentamento de uma questão que atinge a todos: a violência racial e de gênero. Sem dúvida, este tipo de conhecimento, mais amplo e

\footnotetext{
${ }_{11}$ A Casa das Mulheres foi inaugurada em outubro de 2016 e tem por objetivo fomentar o protagonismo das mulheres da região, contribuindo para a melhoria de sua condição de vida e, consequentemente, de todos que as cercam. As atividades se encaixam em diferentes frentes de trabalho: qualificação profissional, enfrentamento das violências contra mulheres, atendimento sociojurídico e psicológico e articulação territorial para a criação de uma agenda positiva nas políticas públicas para este segmento da população.
} 
aprofundado, leva em consideração não só o aspecto teórico, mas as práticas envolvidas - portanto, é um conhecimento que se quer ação, que se pensa como ação.

O intercâmbio de saberes e de pessoas foi um dado significativo para a configuração do estudo. Porém, outro lado desse intercâmbio foi igualmente fundamental, ou seja, aquele veiculado pela associação com a organização Redes da Maré. Para consolidar o suporte a partir do qual foi realizada a pesquisa, é interessante notar o trabalho de formação de alunas/os, por meio da experiência como estagiárias/os e participantes da equipe. Particularmente, a presença de estudantes moradoras/es das localidades da Maré se expressa como um ganho a mais no envolvimento da comunidade com a questão da violência.

\section{A violência armada na Maré}

Os dados do Boletim Direito à Segurança Pública na Maré, aqui destacados, indicam que, em 2017, ocorreram na região: 41 operações policiais; 42 mortes em decorrência de confrontos armados; 41 feridos em operações policiais e 16 em confrontos entre grupos armados; 45 dias com atividades suspensas nos postos de saúde; e 35 dias com escolas fechadas, o que equivale a 17\% dos dias letivos. Ainda a partir da mesma fonte, em relação ao número de intervenções de agentes de Segurança Pública, entre 2016 e 2017, verifica-se a ampliação de 24\% do número de ocorrências. Importante assinalar, no contexto da nossa pesquisa, que a incidência e o aumento nos últimos anos de operações policiais - reflexos de uma política de segurança descontínua e equivocada - efetiva-se de forma diferente no conjunto das 16 favelas que compõem a Maré, e criam níveis de violência diferenciados em cada uma das áreas analisadas (Redes da Maré, 2018 e 2019). Tanto em 2016 quanto em 2017, as operações policiais se concentraram, significativamente, numa região específica do Bairro, onde estão localizadas as favelas Parque União, Rubens Vaz, Nova Holanda e Parque Maré. Todas vinculadas ao grupo Comando Vermelho. Os dados mostram que apenas nessas quatro favelas ocorreram $59 \%$ do total das operações. Não há registro de incursões em áreas dominadas pelas milícias.

No conjunto das favelas pesquisadas há, portanto, lógicas distintas no que diz respeito à ocupação de grupos armados e ao cotidiano de intervenções policiais 
violentas. Nesse sentido, nossa pesquisa de campo reconheceu o conjunto de favelas da Maré como unidade de pesquisa plural e considerou que as especificidades territoriais, inevitavelmente, se revelariam nas situações de violência sofridas pelas mulheres e nas diversas formas de seu enfrentamento.

Nessa ótica, entendemos que a violência se expressa com singularidades na vida de mulheres, especialmente das mulheres negras, que moram em favelas e de forma ainda mais específica nas mulheres que residem na Maré. Há, portanto, a nosso ver, um contexto de violências que incidem socialmente nas experiências de vida, tanto no âmbito público como privado, de mulheres da Maré, que consideramos reflexo das violências contra mulheres na sociedade de maneira geral e com todas as consequências objetivas do patriarcado e do racismo estrutural presentes no Brasil.

Trabalhamos com a perspectiva, portanto, de que a Maré é um conjunto de favelas, não uma unidade homogênea, e as especificidades territoriais inevitavelmente se constituem nas formas como cada uma dessas favelas/áreas experienciam situações de violência e de enfrentamento. Esta perspectiva está, portanto, alinhada à premissa de que estamos lidando com várias favelas, que vivem lógicas distintas no que diz respeito à ocupação de grupos armados e ao cotidiano de intervenções policiais violentas. A partir da lógica territorial, reconhecemos que há grupos armados e ações dos entes estatais - estes últimos deveriam ser responsáveis pela provisão do direito à Segurança Pública - que conformam realidades diferentes e, somadas ao histórico da habitação e à origem sociocultural dos moradores, se apresentam como fatores que impactam nos tipos e nas dinâmicas de violência que as mulheres vivenciam nesses territórios. Os grupos civis armados e paramilitares impõem dinâmicas específicas a cada área da Maré, bem como a lógica de atuação das polícias se dá de forma distinta, e isto, por sua vez, se configura como um dos elementos responsáveis pela heterogeneidade das favelas da Maré, visto que seus moradores/as vivenciam a violência de formas diferentes, e como são suas estratégias de resiliência (KRENZINGER et al., 2018). Esse cenário de violência constante pode ser ainda mais intensificado em situações como a ocupação da Maré pelo Exército brasileiro, entre abril de 2014 e junho de 2015, que teve como objetivo estabelecer as bases para implantação da Unidade de Polícia Pacificadora (UPP) na Maré, quando naquela ocasião a Maré era "controlada" por quatro grupos civis armados (GCA): 
Comando Vermelho (CV), Terceiro Comando (TC), Amigos dos Amigos (ADA) e Milícia (Silva, 2017, p.16).

No conjunto das 15 favelas pesquisadas, percebemos, contudo, que haveria lógicas distintas no que diz respeito à ocupação de grupos armados e ao cotidiano de intervenções policiais violentas. Nesse sentido, nossa pesquisa de campo, ao reconhecer o conjunto de favelas da Maré como unidade de pesquisa diversa e plural, considerou que as especificidades territoriais inevitavelmente se revelariam nas situações de violência sofridas pelas mulheres e nos modos de enfrentamento dessa diversidade de violências que atingem seus moradores. Ao mesmo tempo, de forma generalizada, a violência urbana endêmica se revelou como um efetivo 'gatilho urbano' que propicia formas particulares de violências de gênero e que afeta fortemente a experiência urbana de mulheres (Mcllwaine et al., 2020). Por um lado, agentes armados, como a polícia, foram apontados como frequentes perpetradores de violências contra mulheres e meninas. Outros atores armados, como integrantes do tráfico, são também apontados como perpetradores - nas formas de agressão e de exercício de poder territorial - mas também como agentes de 'proteção' na ausência de forças de segurança do Estado dispostas a apoiar as mulheres dentro de favelas. De modo geral, o problema da violência em favelas é sabidamente um fator que compromete a vida urbana plena. Silva (2009, p. 247) observou que a satisfação dos moradores da Maré com a qualidade de vida é inversamente proporcional ao grau de violência - uma vez que em favelas nas quais a violência é menos conflagrada, principalmente, porque os agentes de Segurança Pública atuam de forma extremamente diferenciada, e apesar de situação mais precária no que se refere a serviços e infraestrutura, quase $90 \%$ das pessoas entrevistadas declararam gostar de morar na Maré. Além disso, 75,5\% dos moradores entrevistados para a pesquisa da referida autora apontou a violência ou elementos relacionados a ela como os principais pontos negativos de se morar na Maré, o que desmistifica o "senso comum" de que moradores/as de favela se acostumaram ou naturalizam a violência e, de certa forma, revelam o medo e a sensação de insegurança dos seus habitantes. Por outro lado, mesmo identificando a violência e seus elementos correlatos como os aspectos mais negativos de viver na Maré, $67,3 \%$ dos/as moradores/as declararam que se sentiam mais seguros na Maré do que no restante da cidade (SILVA, 2009, p. 272). 
No paradigma de cidades justas, seguras e saudáveis para mulheres (vide Mcllwaine et al., 2020), é fundamental, para a compreensão dos entraves da violência ao direito à cidade com igualdade de gênero, reconhecer que a violência de gênero se desenvolve em diferentes escalas, domínios e territórios e, por sua vez, as cidades estão situadas em relações mais amplas de violência estrutural que também mediam e influenciam a natureza da violência de gênero. Assim, tendo em vista estes desafios urbanos, cabe salientar que um dos aspectos mais importantes trazidos à tona pelos questionários e entrevistas com as mulheres da Maré sobre a questão da violência diz respeito ao imbricamento entre relações étnico-raciais, de classe e de gênero - ponto destacado a seguir.

\section{Violências de gênero e desigualdades étnico-raciais no Brasil e na Maré}

Ao longo dos anos, as estatísticas vêm demonstrando o lugar subalternizado das pessoas afrodescendentes no Brasil. Piores condições de vida as acompanham historicamente e abrangem, desde índices inferiores de inserção no mercado de trabalho, passando por piores salários, maior taxa de mortes violentas e de encarceramento. ${ }^{12}$

Especificamente em relação à segurança desta parcela da população, a desigualdade se repete. O Atlas da Violência 2019 (Brasil, 2019) regularmente apresentado pelo Instituto de Pesquisa Econômica Aplicada (IPEA) e pelo Fórum Brasileiro de Segurança Pública (FBSP), por exemplo, informa que, em 2017, 75,5\% das vítimas de homicídios em todo o País são pessoas negras. ${ }^{13}$ É preciso frisar que todos os índices se referem a cerca de 55,5\% da população do País que em 2018 era a dimensão da população negra, segundo dados do IBGE (Brasil, 2018), e expressam a extensão da desigualdade étnico-racial no Brasil.

No País, a conjugação violência-população negra é inequívoca, com desdobramentos, entre os homens, particularmente os jovens, nas taxas de

\footnotetext{
12 Para um panorama completo atualizado em 2018, referente aos dados da população brasileira por cor ou raça, cf. IBGE, acesse <https://biblioteca.ibge.gov.br/visualizacao/livros/liv101681_informativo.pdf.>

${ }^{13}$ Esses dados tiveram como base informações do Ministério da Saúde em relação às cidades brasileiras no ano de 2017. O relatório foi lançado em junho de 2019 e está disponível em <http://www.ipea.gov.br/ atlasdaviolencia/download/19/atlas-da-violencia-2019>
} 
homicídios, como consta no relatório elaborado pelo IPEA/FBSP (Brasil, 2019). ${ }^{14} \mathrm{~A}$ pesquisa registra um panorama histórico de piora nos indicadores, pois, comparandose com relatórios de anos anteriores, na última década a letalidade entre as pessoas negras cresceu $33,1 \%$, contra um crescimento, no mesmo período, de $3,3 \%$ entre indivíduos não negros. O relatório constata "a continuidade do processo de profunda desigualdade racial no País" e que, diante deste quadro, "fica evidente a necessidade de que políticas públicas de segurança e garantia de direitos devam, necessariamente, levar em conta tais diversidades" (p. 51).

Concomitantemente, o encarceramento em massa nos apresenta dados incisivos sobre as desigualdades raciais no momento da consideração do que é "crime" e da pena envolvida. Assim, em seu último levantamento nacional sobre a população carcerária, em junho de 2017 , o Infopen ${ }^{15}$ registra que $63,6 \%$ das pessoas presas são negras. Segundo consta na PNAD Contínua do mesmo período - 2017 a população negra no País representa $55,4 \%$ da população total brasileira, o que indica uma sobrerrepresentação desta etnia/raça nas prisões brasileiras. Este dado reforça as acusações recorrentes, feitas por ativistas negros e estudiosos do tema, de indícios de discriminação étnico-racial pela polícia e órgãos de Segurança Pública ao longo do tempo, que seguem proporcionando barreiras no caminho da população brasileira descendente de africanos.

Desta forma, historicamente, os dados não podem ser dissociados da condição de escravização de africanos que durante séculos formou a base econômica do País, nem do arranjo pós-abolição, que privilegiou em sua busca pela consolidação do capitalismo industrial a importação de mão de obra imigrante europeia e a exclusão dos agora não escravizados. Assim, mesmo com a mudança do modo de produção, não houve efetiva política do Estado brasileiro que incorporasse, no novo esquema, essa grande parcela da população; pelo contrário, a desigualdade étnico-racial se perpetuou e se inseriu de forma estrutural no nascente capitalismo brasileiro, como demonstrou Hasenbalg (1979).

Os dados relativos à raça/cor no Brasil apresentam, ainda, em termos de local e condições de habitação, a concentração da população preta e parda nos locais mais

\footnotetext{
${ }_{14}$ Atlas da Violência (Brasil, 2019), p. 49. Disponível em <http://www.ipea.gov.br// atlasdaviolencia/ download/19/ atlas-da-violencia-2019>

15 O Infopen é um sistema de informações estatísticas do sistema penitenciário brasileiro (estabelecimentos penais e população prisional), em funcionamento desde 2004.
} 
insalubres e precários em termos de moradia urbana. Neste sentido, voltando os olhos para a pesquisa realizada na Maré, não surpreende o percentual de mulheres pretas e pardas: $67 \%$ das 801 respondentes. Em contrapartida, apenas $30 \%$ se declararam mulheres brancas. ${ }^{16}$

Em relação a esta classificação por raça/cor, um dado considerado significativo pelas pesquisadoras é o de que 13 pessoas declararam "não saber" sua cor. Para entender melhor esta questão, há de se recorrer à literatura sobre relações étnicoraciais no Brasil. Nogueira (1985), por exemplo, já destacava que o exercício de classificação de cor no Brasil envolve algumas associações e indicadores que vão além da cor da pele ou da origem étnica. Segundo o autor, o gestual, alguns traços físicos específicos - notadamente o formato do nariz, o tamanho da boca e o tipo de cabelo - o modo de se vestir e mesmo a forma de falar são utilizados como meios de indicar se uma pessoa é de ascendência europeia ou afrodescendente. Ainda de acordo com Nogueira (1985), o exercício da classificação dependerá, mais do que a referência a uma origem africana, de um cálculo em que o aspecto relacional estará presente - assim, ser "mais claro" ou "mais escuro" do que o/a interlocutor/a será um esforço empreendido pela pessoa ao ser perguntada sobre sua cor.

Este aspecto interativo da classificação entra em jogo no momento mesmo em que foram realizadas as entrevistas no campo. Daí a relevância heurística, sem falar na importância ética, nesta direção, de contarmos com uma equipe de pesquisadoras de diferentes pertencimentos étnico-raciais, de modo a provocar e a incluir esta forma de classificação como dado de pesquisa e reflexão. É compreensível que, dada a complexidade do exercício de classificação de cor assim elaborado, muitas vezes os/as entrevistados/as prefiram o silêncio, ou a alternativa "não sabem", em questionários com a pergunta direta sobre autoclassificação de cor. Importante verificar, na pesquisa em questão, que a grande incidência de pessoas de origem nordestina na Maré - $88 \%$ dentre as $38 \%$ não cariocas vieram do Nordeste - provoca reflexões nas respondentes: como alertaram diversos estudos, muitas vezes esta classificação, o "ser nordestina", é compreendida em alguns circuitos de interação social como um tipo de classificação "racial".

${ }^{16}$ Nas entrevistas da pesquisa, foi utilizado o recurso da autodeclaração, dentro das opções estabelecidas pelo IBGE: branca, parda, preta, indígena e amarela. 
Afinal, como frisa Guimarães (1999), "o racismo e o 'preconceito de cor' são formas racializadas de se naturalizar a segmentação da hierarquia social. A racialização desta hierarquia pode, inclusive, ajustar-se, segundo as regiões e o tempo histórico, provendo sucedâneos simbólicos aos 'negros', como são, no Sudeste brasileiro, os epítetos de 'baianos', 'paraíbas' e 'nordestinos'” (p. 27). Desta maneira, muitas pessoas, acostumadas a serem classificadas como "nordestinas", quando perguntadas sobre sua raça/cor, podem ter em mente sua origem territorial como forma de resposta, e se sentiram pouco confortáveis em decidir a partir das categorias estabelecidas pelo IBGE e constantes no Censo Demográfico. ${ }^{17}$

Portanto, violência e raça/etnia são termos que se articulam dolorosamente desde a chegada dos primeiros africanos escravizados no Brasil, assim como em outras partes do mundo. ${ }^{18} \mathrm{~A}$ subordinação à força, a condição de desumanização, as torturas estavam ligadas ao processo de escravização desde o embarque dos prisioneiros em portos africanos, até sua chegada ao Brasil - assim, dados indicam que por volta de 4,9 milhões de pessoas vieram escravizadas para o País, enquanto cerca de 690 mil morreram neste deslocamento. Após a chegada, a sujeição, a separação de famílias e povos, a negação de sua cultura, religião e crenças, os castigos e o trabalho em condições desumanas faziam com que, por exemplo, no cultivo da cana, a expectativa de vida de uma pessoa escravizada fosse de 23 a 29 anos (GOMES e SCHWARZ, 2018).

As diversas estratégias de resistência a esta situação extrema foram rebeliões e revoltas, "mutirões" para compra de alforrias, fugas coletivas e formação de comunidades próprias (quilombos), passando ainda pela articulação com segmentos

\footnotetext{
${ }^{17}$ Estas categorias, aliás, ao longo do tempo, têm sido objeto de diversas disputas e polêmicas, e está longe de ser uma unanimidade até hoje. Em 1976, por exemplo, foi realizada ampla pesquisa sobre classificação étnico-racial, pelo IBGE - a Pesquisa Nacional por Amostra de Domicílios. Nela, havia duas perguntas relacionadas à classificação de cor: a primeira convidava os interlocutores à autoclassificação espontânea, com a resposta em aberto; já a segunda, apresentava as quatro categorias tradicionais do Censo: preta, parda, branca e amarela, para que o/a respondente optasse. O resultado à questão aberta foi um leque de 136 termos para cor (para uma análise aprofundada dos dados da PNAD 1976, ver Araújo, Porcaro e Oliveira, 1985; e o excelente trabalho de Silva, 1988).

${ }^{18}$ Calcula-se que em mais de três séculos os chamados "navios negreiros" fizeram cerca de 9,5 mil viagens destinadas ao tráfico de pessoas africanas escravizadas, trazendo, apenas para o Brasil, 4,9 milhões de pessoas. Os países que mais transportaram africanas/os na condição de escravas/os foram Inglaterra e Portugal. Estes dados, assim como vários outros referentes ao tráfico, estão disponíveis em The Transatlantic Trade Slave Database, plataforma digitalizada que abrange 35 mil expedições entre 1514 e 1866, resultado do esforço de pesquisadores de instituições de vários países, principalmente ligados às Universidades de Harvard e de Emory (EUA) e de Hull (Reino Unido) em recolher e catalogar os registros do transporte das pessoas escravizadas, registradas como mercadoria.
} 
liberais brancos na campanha abolicionista, formação de redes de solidariedade religiosa (as Irmandades) e mesmo atitudes individuais mais agônicas - estudos mostram, por exemplo, a grande quantidade de suicídios entre os escravizados, particularmente mulheres (KARASCH, 2001).

Com a transição para um regime capitalista de grande dependência externa, os descendentes de africanos se viram às voltas com outros tipos de exclusão e violência. Com uma política oficial voltada para a absorção de mão de obra imigrante e não para a inclusão daquela já existente no País - os descendentes de africanos e a intenção muitas vezes explicitada de "branqueamento da população" brasileira, este novo modo assalariado de produção resistiu à inclusão do povo negro, que se viu à mercê dos empregos mais precarizados e distantes dos grandes centros industriais que então passaram a se desenvolver. ${ }^{19}$

O novo modo de produção no Brasil, dessa forma, significou a inserção subalternizada na nova estrutura socioeconômica. Assim, sem políticas de acesso à terra onde haviam trabalhado brutalmente, com acesso restrito aos novos postos industriais que surgiam, sem implementação de medidas inclusivas na educação e na habitação, os descendentes de africanos se viram diante de um novo modo de produção que significou sua inserção subalternizada na nova estrutura social, impedindo qualquer mobilidade social. Nesta direção, a desigualdade social passaria a se perpetuar a partir do acréscimo de outra dimensão: a da discriminação racial. Em suma, não apenas o processo de escravização condicionou a desigualdade que se estende até os dias de hoje, mas sobretudo a ausência de políticas e ações de inclusão efetivas no período imediatamente após a abolição.

A situação das mulheres escravizadas, em relação à violência, conta ainda com a sobreposição de alguns fatores específicos, como a violência sexual generalizada. Como propriedades, as mulheres africanas e suas descendentes eram compreendidas como escravas sexuais. Segundo Stolcke (2007), o cenário se completava com a prescrição de lugares sociais de mulheres segundo a cor: às mulheres brancas era destinado o papel de "esposa e mãe", exercidos dentro de um espaço doméstico e cujo proprietário era o marido; para as mulheres negras, e as indígenas, nenhum dos dois papéis era possível - no máximo, seriam consideradas ${ }_{19}$ Para compreender melhor esta distribuição geográfica entre a cidade reservada aos brancos, e o
campo, aos negros, ver Hasenbalg, 1979 . 
"amantes", e seus filhos não teriam direito à herança. Com esta escala hierárquica que compunha os lugares sociais das mulheres brancas, pardas e pretas, segue a autora, os bens adquiridos com a pilhagem colonial e com o trabalho das pessoas escravizadas eram transmitidos diretamente aos membros da elite colonial branca.

Ainda durante a época da escravização, as mulheres africanas e descendentes foram associadas ao trabalho doméstico e de cuidados nas casas das famílias brancas. Além disso, formavam grande parte das pessoas designadas como "escravas de ganho", ou seja, aquelas que tinham acesso ao espaço da rua para venda de produtos agrícolas, comidas e até serviços sexuais, cujo ganho era transferido e controlado por seus patrões brancos. Assim, a circulação dessas mulheres se dava tanto no espaço público da rua quanto no doméstico - porém, na condição subalternizada de escrava, inclusive escrava sexual.

Voltando os olhos para a contemporaneidade, merecem atenção os dados relativos à violência de que são vítimas as mulheres negras. No citado relatório do IPEA/FBSP, encontramos índices gerais preocupantes em relação ao homicídio de mulheres - só no ano de 2017, foram mortas cerca de 13 mulheres por dia, o maior índice em 10 anos - quando os homicídios são desagregados por cor, temos que, enquanto a taxa para mulheres não negras subiu 1,6\%, entre 2007 e 2017, a de mulheres negras cresceu 29,9\%. Isso significa um aumento de 1,7\% para mulheres não negras e de 60,5\% para mulheres negras. No caso das mulheres negras, e das mulheres em geral, a maioria das agressões e homicídios se dá dentro da residência e por perpetrador conhecido ou familiar da vítima. Quanto ao Rio de Janeiro, o Dossiê Mulher 2018 elaborado pelo Instituto de Segurança Pública/RJ afirma que duas em cada três mulheres vítimas de homicídio doloso no estado do Rio eram negras.

No âmbito da pesquisa na Maré, alguns dados fazem eco a este cenário geral. Entre as entrevistadas, há o reconhecimento das violências de gênero, particularmente aquela associada a um território estigmatizado socialmente, como comentado; assim, quando perguntadas sobre se existe violência contra mulheres e meninas na Maré, $76 \%$ das mulheres afirmaram que sim, 18\% afirmaram não saber e $6 \%$ disseram que não há. Quando se relaciona os relatos de violência à cor declarada pelas mulheres, temos $24 \%$ de mulheres brancas afirmando que sofreram violência, contra $31 \%$ das mulheres pretas e pardas - uma expressiva diferença que corrobora os dados sobre violência contra a população negra apresentados. 
Quanto ao tipo de violência, foram descritas: a violência física (agressão física, contato físico indesejado, controle violento, estrangulamento, queimadura e esfaqueamento); a violência sexual (comentários sexuais, atos sexuais indesejados e estupro); e a violência psicológica (ameaças de agressão física, comentários negativos e abuso verbal). Das 801 mulheres entrevistadas, 457 (57\%) relataram ter sofrido violência; destas, 317 (69,3\%) eram negras (soma de mulheres pretas e pardas). As mulheres pretas e pardas estão em maioria entre aquelas que sofreram violência física - $190(69,8 \%)$ de um total de 272 mulheres; entre as que sofreram violência sexual - $174(71,6 \%)$ entre 243 no total. Já entre as que foram vítimas de violência psicológica, as mulheres pretas e pardas somam 252 (69,4\%) de um número total de 363 vítimas deste tipo de violência.

A contínua desvalorização estética negra em favor de um modelo branco de beleza, processo histórico e que se mantém até os dias de hoje (a respeito disso, ver o instigante e pioneiro trabalho de Guerreiro Ramos, 1995), além da exclusão de pessoas negras dos espaços onde o maior número de pessoas é branco e de camadas mais abastadas da população - a chamada segregação residencial contribuem igualmente para causar o fenômeno que diversas estudiosas e militantes analisaram: a "solidão da mulher negra" (BERQUÓ, 1987; PACHECO, 2013). Assim, a taxa de mulheres negras solteiras, ou chefes de família, ou com relações não estáveis estatisticamente é maior do que a de mulheres brancas. No Censo de 2010 (Brasil, 2010), por exemplo, verificou-se que $52,5 \%$ das mulheres negras não viviam em união (categoria utilizada pelo Censo).

Em princípio preteridas por estes fatores para relações duradouras por homens brancos e negros, as mulheres negras que ultrapassam tais obstáculos se veem às voltas com complicadores nas relações afetivo-sexuais que constroem. Racismo, inferiorização estética e desvalorização podem contribuir para torná-las mais suscetíveis a sofrerem violências do parceiro afetivo-sexual.

Esta constatação leva a outra reflexão importante sobre as dinâmicas de raça e classe, conectando-as aos processos de mobilidade urbana. Phadke, Ranade e Khan (2009), em estudo sobre a mobilidade urbana das mulheres e dos homens em Nova Delhi, na Índia, corroboram que a circulação feminina na cidade é restrita, funcionando a partir da dicotomia ocidental tradicionalmente apontada pelos estudos feministas clássicos: uma esfera/espaço público de predominância masculina e uma 
esfera/espaço privado onde as mulheres majoritariamente são alocadas. No entanto, afirmam que esta restrição não é absoluta - pois desde há muito, por exemplo, as mulheres das castas mais baixas, no caso indiano, frequentam as ruas e as casas alheias em busca de sustento; no caso brasileiro, há séculos as mulheres negras frequentam e trabalham dentro e fora de suas casas, como escravas domésticas e de ganho, primeiro e, em seguida, como trabalhadoras subalternizadas. Neste sentido, casta (na Índia), e classe e raça (no Brasil) são indicadores dos lugares sociais e dos espaços possíveis de serem ocupados por homens e mulheres na cidade. ${ }^{20}$

Num cenário capitalista em que o consumo de mercadorias é um pilar estrutural, a divisão dos espaços públicos e privados por gênero e classe, além de não ser absoluta, é também seletiva. Não só as figuras das "mulheres trabalhadoras" são aceitas como legítimas partícipes dos espaços urbanos, mas as "mulheres compradoras" são permitidas e legitimadas nas ruas. No entanto, em ambos os casos - o das compradoras e o das trabalhadoras - é preciso que sejam respeitados determinados locais e horários, ou seja, fora do "horário comercial", e especialmente à noite, nos locais públicos como ruas e esquinas, bares, boates e eventos festivos, o acesso feminino é considerado socialmente indesejável, classificando as mulheres que circulam por estes espaços nestes horários como tendo um "caráter moralmente reprovável". ${ }^{21}$

\section{Considerações finais}

Apesar de reconhecidas, em nível mundial, como uma das melhores legislações que buscam enfrentar o problema da violência contra a mulher, as leis Maria da Penha (Brasil, 2006) e do Feminicídio (Brasil, 2015) não foram suficientemente inibidoras da violência de gênero no Brasil. No mesmo sentido, o celebrado Estatuto da Cidade (Brasil, 2001) não assegurou efetivo direito à cidade para mulheres, especialmente as negras e periféricas. Mesmo com o avanço da

\footnotetext{
${ }^{20}$ Sobre a relação entre classe, raça e gênero expressa nas opostas perspectivas sobre o significado histórico do trabalho, da casa e da rua para mulheres negras e brancas, ver Carneiro, 2019.

${ }^{21}$ Rabossi (2004) indicou que o espaço público em Ciudad del Este, vizinha a Foz do Iguaçu, era frequentado tanto por homens quanto por mulheres, nos papéis de "compristas" (consumidoras) ou comerciantes informais; no entanto, quando caía a noite na cidade, a presença nestes espaços se tornava eminentemente masculina.
} 
legislação e do engajamento social ao tema, a redução significativa da desigualdade de gênero/raça ainda está longe de ser uma realidade no País. Pelo contrário, nos últimos quatro anos, sofremos vários reveses limitando os espaços recémconquistados, bem como uma significativa redução dos investimentos e recursos destinados às políticas de combate à violência contra a mulher.

Nesse aspecto, a realização de uma pesquisa sobre violência num território com as especificidades da Maré/RJ reuniu um acervo de dados valioso para subsidiar a construção de novos caminhos para o enfrentamento da temática da violência de gênero. Ter ouvido um conjunto expressivo de mulheres constituiu uma oportunidade rica de significados para todos os envolvidos nesta pesquisa. Os repertórios sobre violência, questões de gênero, relações étnico-raciais e outros temas foram densos e sugestivos para um investimento maior no debate sobre a violência contra mulheres, bem como nas formas de enfrentamento desenhadas para mulheres em geral, e mulheres com perfis semelhantes às que vivem na Maré ou fora dela.

Se relacionarmos os dados apresentados ao contexto brasileiro, temos um quadro em que as complexidades e intersecções das desigualdades de gênero, raça/cor e classe se mostram de forma aguda. Assim, ao se refletir sobre os índices referentes às violências contra as mulheres negras, o encarceramento e o homicídio massivos de homens negros, pode-se dizer, em suma, que o fenômeno da violência acompanha a população negra em suas diferentes manifestações e territórios. Desta forma, se a rua é o ambiente em que mais homens negros são mortos, por exemplo, a casa é onde há maior incidência de violência doméstica, que atinge principalmente mulheres negras. Para esta parcela da população, não existe ambiente seguro.

$\mathrm{Na}$ pesquisa realizada na Maré, as depoentes relatam que a violência se espraia tanto no cenário privado como no público, com uma ligeira vantagem deste último, onde ocorrem a maioria dos casos de violência psicológica - de comentários ofensivos a ameaças físicas e/ou sexuais. E como citado, grande parte das entrevistadas que sofreram este tipo de violência são pretas ou pardas.

É preciso considerar, ainda, que o entendimento conceitual sobre violência de gênero deve ser analisado e enfrentado de uma perspectiva transnacional, como um fenômeno que atinge mulheres, especialmente as mulheres negras, nas mais diversas nações e territórios do mundo. No presente estudo, a atenção a esta perspectiva permitiu, por exemplo, a reflexão sobre as conexões que unem e perpetuam as 
múltiplas manifestações das violências contra as mulheres moradoras da Maré e as brasileiras que residem em Londres.

A dinâmica de desigualdades superpostas e mescladas precisa ser levada em conta em qualquer desenho de políticas públicas, particularmente aquelas relacionadas à saúde e à Segurança Pública. Esse contexto de realização da pesquisa e a escolha metodológica têm, então, relação objetiva com as variáveis que incidem no cotidiano de territórios conflagrados onde há uma frágil presença do Estado de Direito (que se evidencia na precariedade de serviços públicos e na parca garantia de direitos, entre os quais, naturalmente, o direito à Segurança Pública), que se concretiza numa polícia que atua recorrentemente de forma muito violenta.

É nesta direção que se compreende o presente estudo, como uma contribuição rumo à construção de políticas de enfrentamento às violências que integrem de forma mais aprofundada as dimensões de raça/cor, gênero, classe social e de território presentes nas sociedades contemporâneas.

A dimensão política da violência de gênero é visível pelo grau de tolerância do Estado. Tal tolerância é traduzida pela ausência ou deficiência de políticas públicas capazes de gerir o problema em sua complexidade (o que inclui, necessariamente, a dimensão preventiva); pela sustentação do fenômeno pelo poder público, expressa no seu (não) enquadramento legal (o que engloba a intervenção do aparato policialjudiciário), ou pela estratégia governamental de reafirmar lugares de gênero hegemonicamente distribuídos. A questão da tolerância do Estado e de sua histórica indolência com as questões que envolvem direitos humanos - e aí, não somente os das mulheres - sempre deverá ser analisada a partir das dinâmicas sociais e políticas.

\section{Referências}

ALMEIDA, S. Essa violência mal-dita. In: ALMEIDA.S.(org.) Violência de Gênero e Políticas Públicas. Rio de Janeiro: Ed. UFRJ, Série Didáticos, 2007, pp. 12- 24.

ARAÚJO, T. C.; PORCARO, R.M.; OLIVEIRA, L.E.G. O lugar do negro na força de trabalho. IBGE, 1985.

BERQUÓ, E. Nupcialidade da população negra no Brasil. In: Textos NEPO, n. 11, pp. 8-46, agosto de 1987.

BRASIL. INSTITUTO DE PESQUISA ECONÔMICA APLICADA (IPEA); FÓRUM BRASILEIRO DE SEGURANÇA PÚBLICA (FBSP). Atlas da Violência 2019. 
Disponível em http://www.ipea.gov.br/atlasdaviolencia/download/19/atlasda- violencia-2019

BRASIL. INSTITUTO BRASILEIRO DE GEOGRAFIA E ESTATÍSTICA (IBGE).

Pesquisa Nacional por Amostra de Domicílios Contínua. 2018a. Disponível em https://www.ibge.gov.br/estatisticas/sociais/populacao/17270-pnad-continua.htm

Disponível

Desigualdades sociais por cor ou raça no Brasil. 2018b. https://biblioteca.ibge.gov.br/visualizacao/livros/liv101681_informativo.pdf

em

. Censo $2010 \quad$ Disponível em

https://www.ibge.gov.br/estatisticas/sociais/saude/9662-censo-demografico-2010

. Presidência da República. Lei no 13.104, de 09/03/2015 (Lei do Feminicídio). $\overline{\text { Altera }}$ o art. 121 do Decreto-lei no 2.848, de 7 de dezembro de 1940 - Código Penal, para prever o feminicídio como circunstância qualificadora do crime de homicídio, e o art. 1ํㅡㄹ da Lei $n^{\circ} 8.072$, de 25 de julho de 1990, para incluir o feminicídio no rol dos crimes hediondos. Brasília/DF: DOU, 2015.

. Presidência da República. Lei no 11.40, de 07/08/2006 (Lei Maria da Penha). Cria mecanismos para coibir a violência doméstica e familiar contra a mulher, nos termos do $\S 8^{\circ}$ do art. 226 da Constituição Federal, da Convenção sobre a Eliminação de Todas as Formas de Discriminação contra as Mulheres e da Convenção Interamericana para Prevenir, Punir e Erradicar a Violência contra a Mulher; dispõe sobre a criação dos Juizados de Violência Doméstica e Familiar contra a Mulher; altera - Código de Processo Penal, o Código Penal e a Lei de Execução Penal; e dá outras providências. Brasília/DF: DOU, 2006.

. Presidência da República. Lei no 10.257, de 10/07/2001 (Estatuto da Cidade). Regulamenta os arts. 182 e 183 da Constituição Federal, estabelece diretrizes gerais da política urbana e dá outras providências. Brasília/DF: DOU, 2001.

CARNEIRO, S. Enegrecer o feminismo: a situação da mulher negra na América Latina a partir de uma perspectiva de gênero. In: Buarque de Hollanda, H. (org.), Pensamento feminista. Rio de Janeiro: Bazar do Tempo, 2019, pp. 313-322.

FARIAS, P. S.; CECCHETTO, F. Tu mora onde? Território e produção de subjetividade no espaço urbano carioca. In: Carneiro, S.S.; Sant'anna, M. J. G.(orgs.), Cidade: olhares e trajetórias. Rio de Janeiro: Garamond, 2009, pp. 219-240.

FERNANDES, F. Maré: uma cidade dentro do Rio de Janeiro. Bairros Cariocas. 2015.

Disponível

em

<http://www.multirio.rj.gov.br/index.php/leia/reportagens-artigos/reportagens/3086mare-uma-cidade-dentro-do-rio-de-janeiro>

GOMES, F.; SCHWARZ, L. (orgs.). Dicionário da Escravidão e da Liberdade - 50 textos críticos. São Paulo: Cia. das Letras, 2018. 
GUERREIRO RAMOS, A. Introdução crítica à Sociologia brasileira. Rio de Janeiro: EdUFRJ, 1995.

GUIMARÃES, A. S. Racismo e anti-racismo no Brasil. Rio de Janeiro: Fundação Ford/Editora 34, 1999.

GUIMARÃES, B. Cissexual, cisgênero e cissexismo: um glossário básico. Feminismo $\quad$ Trans. $2013 . \quad$ Disponível em $<$ https://feminismotrans.wordpress.com/2013/03/15/cissexual-cisgenero-ecissexismo-um-glossario-basico>

HASENBALG, C. Discriminação e desigualdades raciais no Brasil. Belo Horizonte: Ed UFMG, 1979.

KARASCH, M. A vida dos escravos no Rio de Janeiro (1805-1850). São Paulo: Cia das Letras, 2001.

KRENZINGER, M. et al., Dores que libertam - falas de mulheres das favelas da Maré, no Rio de Janeiro, sobre violências. Curitiba: Appris, 2018.

MCILWAINE, C.; EVANS, Y. Não se pode lutar no escuro. Violência contra mulheres e meninas brasileiras em Londres. In: KRENZINGER, M. et al. Dores que libertam falas de mulheres das favelas da Maré, no Rio de Janeiro, sobre violências. Curitiba: Appris, 2018, pp. 163-174.

; KRENZINGER, M.; EVANS, Y. SILVA, E. Feminised urban futures, healthy cities and violence against women and girls: transnational reflections from Brazilians in London and Maré, Rio de Janeiro. In: KEITH, M. \& SANTOS, A. Urban transformations and public health in the emergent city. Manchester: Manchester University Press, 2020, pp. 56-78.

MOSER, O. N. C \& MCILWAINE, C 2004. Encounters with Violence in Latin America. Urban Poor Perceptions from Colombia and Guatemala, London: Routledge, 2004.

NOGUEIRA, O. Tanto preto quanto branco - estudos de relações raciais. São Paulo: T. A. Queiroz, 1985.

SIILVA, J. (org.) O que é favela, afinal? Rio de Janeiro: Observatório de Favelas do Rio de Janeiro, 2009.

PACHECO, A. C. L. Mulher negra: afetividade e solidão. Salvador: EdUfba, 2013.

PHADKE, S; RANADE, S; KHAN, S. Why loiter? Radical possibilities for gendered dissent. In: BUTCHER, Melissa; VELAYRITHAM, Selvaraj (eds.). Cultural resistance in Asia's Cities. London and NY: Routledge, 2009.

RABOSSI, F. Nas ruas de Ciudad del Este: vidas e vendas num mercado de fronteira. 2004. 318f. Tese (Doutorado em Antropologia Social) - Museu Nacional/UFRJ, Rio de Janeiro. 
REDES DA MARÉ. Boletim Direito à Segurança Pública na Maré 2019. Rio de Janeiro: Redes da Maré, 2020. Disponível em <https://redesdamare.org.br>

. Boletim Direito à Segurança Pública na Maré 2018. Rio de

Janeiro: Redes da Maré, 2019. Disponível em <https://redesdamare.org.br>

RIO DE JANEIRO. INSTITUTO DE SEGURANÇA PÚBLICA. Dossiê Mulher 2018. Disponível em http://www.isp.rj.gov.br

ROY, A. Cidades faveladas: repensando o urbanismo subalterno. Revista emetropolis, 31, 2018. Disponível em <https://www.observatorio das metropoles.net.br/revista-e-metropolis-cidades-faveladas-repensando-o-urbanismosubalterno/>

SAFFIOTI, H. I. B. Já se mete a colher em briga de marido e mulher. São Paulo em Perspectiva, São Paulo, v. 13, n. 4, p. 82-91, dez. 1999.

SILVA, E. S. A ocupação da Maré pelo Exército brasileiro: percepção de moradores sobre a ocupação das Forças Armadas na Maré. Rio de Janeiro: Redes da Maré, 2017.

O contexto das práticas policiais nas favelas da Maré: a busca de novos caminhos a partir de seus protagonistas. 2009. $460 \mathrm{f}$. Tese (Doutorado em Serviço Social) - Pontifícia Universidade Católica do Rio de Janeiro/PUC, Rio de Janeiro.

SILVA, N. V. Cor e processo de realização socioeconômica. In: SILVA, N. V.; HASENBALG, C. (orgs.), Estrutura social, mobilidade e raça, Rio de Janeiro: Vértice, 1988, pp. 144-163.

SIMONE, A. People as infrastructure. Intersecting fragments in Johannesburg. Public Culture, 16 (3), 2004, pp. 407-429.

STOLCKE. V. Gênero Mundo Novo: Interseções. A formação dos impérios transatlânticos do século XVI ao XIX. In: GROSSI, M. P.; ECKERT, C.; FRY, P. (orgs.), Conferências e diálogos: saberes e práticas antropológicos. Blumenau/SC: ABA/Nova Letra, 2007, pp. 82-116.

THE TRANSATLANTIC TRADE SLAVE DATABASE. Disponível em www.slavevoyages.org

WACQUANT, L. Punir os pobres: a nova gestão da miséria nos Estados Unidos. Rio de Janeiro: Revan, 2001. 